\title{
Perceptions and Challenges of CLT in EFL Classes - Possible Research in Afghan Tertiary EFL Context
}

\author{
Ghazi Mohammad Takal, Noor Mala Ibrahim
}

\begin{abstract}
A great deal of research has been conducted regarding Communicative Language Teaching (CLT) in English as a Second Language (ESL) and English as a Foreign Language (EFL) contexts, including in Afghanistan. However, the real status of CLT employed in Afghan context is vague due to the lack of sufficient studies. The aim of this paper is to present a review on CLT in various EFL contexts in general and on the perceptions and challenges in the implementation of CLT in Afghanistan for the purpose of identifying gap for a subsequent investigation of CLT in the country. The results show that there are still many areas that need to be examined in the Afghan EFL setting to improve the quality of English teaching and learning in Afghan universities.
\end{abstract}

Keywords: CLT, Challenges, Afghan EFL Lecturers, Perceptions

\section{INTRODUCTION}

Communicative Language Teaching, which focusses on communicative competence, has been one of the widely used approaches in English Language Teaching (ELT) classrooms. According to [1], communicative competence is divided into four, which are grammatical (linguistic) competence, sociolinguistic competence, discourse competence and strategic competence. Although CLT is a common teaching methodology today in English as a Second Language (ESL) and English as a Foreign Language (EFL) contexts, in practice, the methodology has been challenged by various factors. There are challenges related to EFL learners, EFL teachers, CLT-related and miscellaneous challenges, which include problems related to classrooms, curriculum, administration, cultural and environmental, to name a few. This paper provides an overview of challenges of the implementation of CLT in $14 \mathrm{EFL}$ contexts around the globe. In addition, the background of CLT, some critical views about CLT, and CLT in Afghan EFL context are discussed. The review also gives the rationale for future investigation into CLT in the Afghan EFL context.

\section{CLT AT A GLANCE}

Many English instructors have claimed to be using Communicative Language Teaching CLT), making CLT one of the currently widely used teaching methods in the world

Revised Version Manuscript Received on April 19, 2019.

Ghazi Mohammad Takal, Department of English, Faculty of Languages and Literature, Ghazni University, Ghazni City, Afghanistan. E-mail: ghazitakal@gmail.com.

Noor Mala Ibrahim, Language Academy, UTM, Johor Bahru, Johor, Malaysia. E-mail:m-nmala@utm.my. since 1990 [2]. In fact, [3] claims that most of the curricula in foreign language teaching employ CLT as a predominant teaching methodology.

According to [4]-[5], CLT came into existence in 1970s in the European countries and entered English language curriculum in 1980s. As [6]-[8] argue CLT should be based on any model of communicative competence, and indeed CLT has been developed based on this concept. CLT does not focus only on grammatical competence as traditional methods did, but it also focuses on the competences beyond linguistic competence such as discourse competence, strategic competence, sociolinguistic competence and grammatical competence [9].

According to [2], ELT has undergone numerous changes in the last fifty years. [2] has divided these changes in three phases of traditional methods (1960s), classical communicative language teaching (1970s-1990s) and current communicative language teaching (1990s-up to present). [10] claim that the significant features of CLT (learner autonomy, the social nature of learning, focus on meaning, diversity, thinking skills, alternative assessments, and teachers' role as co-learners) have made CLT widely accepted and appropriate teaching method for various settings.

In addition, other scholars [11]-[13] agree CLT is one of the influential and important methods in language teaching in various contexts. CLT has been introduced in Asian countries in 1990s for English as a Foreign Language (EFL) due to the needs of EFL at the time [11];[13]. However, numerous scholars [11]-[18] believe that the effective implementation of CLT in Asian EFL contexts, is faced with various challenges which are summarized in the following bar graph.

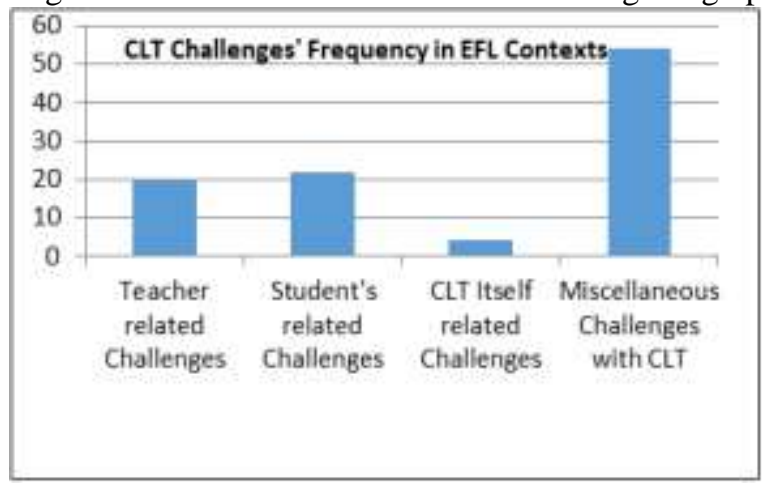

Fig 1: Bar graph showing frequency of challenges with CLT in EFL contexts 


\section{CHALLENGES OF CLT IN EFL CONTEXT}

The literature shows that there has been no study which can confirm to a great extent the success on the implementation of CLT. What the literature has been able to show is that the majority of the challenges faced in the implementation of CLT is the same from one context to another. The bar graph in Fig 1 demonstrates that miscellaneous challenges are on the top. One of the very common challenges in ESL and EFL contexts that have been reported by a great number of researchers (e.g.: [5];[19]-[22]) is the lack of materials (authentic materials) to prepare students for real-life situations, particularly when opportunities to communicate in English outside classrooms is very limited. [23] argues that most of the literature (and in fact his own study) have failed to describe the classroom environment as authentic and so concludes that CLT cannot provide authentic communication. [24] also agrees that CLT enthusiastic teachers could not overcome providing real-life situations in the classroom to promote learners' communication skills, again implying the difficulties in providing authentic communication for learners when applying CLT in classrooms.

[23] then further argues that CLT has not been fully successful in fulfilling its promises to bring innovation in the educational world. In brief, the foremost fault of CLT is, therefore, the very first premise of CLT that is the lack of "communicativeness" in the word "communicative" in CLT.

Studies from Bangladesh [25], Thailand [19], Japan [26], Taiwan [22], China [21] reported the cultural mismatch between CLT and students, grammar-based examinations, as socio-cultural factors obscuring CLT application. This is in line with previous researchers (e.g.: [23]; [27]-[29]) who believe that the reason why CLT could not adapt all contexts is that CLT cannot make some of its features like socio-cultural factors compatible with certain contexts. One of the conflicting socio-cultural features of CLT is the lack of distinction between ESL and EFL teachers. For instance, there are differences of the role of teachers and learners in eastern and western communities. [14], for example, strongly believes that the role of teachers differs from ESL to EFL contexts. The teacher in EFL classroom is the sole provider of knowledge for the learners since there is no chance of learning outside of the classroom. However, the ESL teacher can only act as a facilitator since the learners could have ample access to social interactions and thus, most of the learning may occur outside of the classroom. Yet, this is the distinction that has not received much attention in CLT practices. Culture may also offer negative impacts on CLT. For instance, many cultures expect the students to respect their teachers and do not voice their opinions even if the teacher is wrong, which is in contrast with CLT tenets.

Many other scholars [27]-[30] also believe that learner-centeredness in CLT is also a challenge in the contexts where the hierarchy for social relationship is from top to down. Furthermore as [31] argue, many students know the importance of communicative activities; but because of the grammar-based exams they feel unmotivated towards communicative activities. Many of these students may focus more on passing the examinations rather than participating in

interactions in the classrooms.

The bar graph in Fig 1 also shows that the literature reports that the second and third major challenges are related to students and teachers. The biggest challenges for CLT with students is their weak proficiency reported in many studies in Afghanistan [32], Taiwan [22], Saudi Arabia [33], Ethiopia [20], and Libya [34]. There could be different causes for low proficiency of learners in a CLT class. For instance, CLT focuses on using target language and no preference to using mother tongue in classroom while students are having limited knowledge of structures and grammar in the target language. This thus is a major challenge which may lead to CLT being unsuitable for low proficiency learners [35]. Low proficiency of the learners may also be a result from the use of traditional methods prior to the implementation of CLT in the classroom. In traditional methods, students are exposed to form-based instruction in which mistakes while learning are not tolerable. Hence, when CLT is practiced, many students are afraid of making mistakes while participating in discussions, group and pair works in a class [36]. This leads to the loss of motivation to participate in a CLT class activities due to the fear of making mistakes. As a result, low proficient learners will mostly depend on their high proficient peers during CLT class activities [26]. In addition, the challenges involving teachers in EFL settings could hinder CLT successful implementation. Studies from Afghanistan, Thailand, Iran, Taiwan, Bangladesh, China and Chile have found that teachers have problems in CLT application in teaching. These studies show that the major challenge for CLT teachers is teachers' lack of knowledge in CLT [11]; [15]; [32]; [36]-[37].

The problems in education system and administration that prevent CLT application cannot also be negleted. On the top of this is the issues of large class and the lack of funding for CLT classes. Administrative support is considered a necessary component for the success of CLT ([11]; [15]; [18]; [38]). Many of the previous studies from the aformentioned EFL contexts of Taiwan [22], Iran [39], Bangladesh [18], China [21] have cited large classes a challenge to CLT application. For example, [22] found that 59\% of the respondents in Taiwan veiwed large classes as a challenge to CLT implementation suggesting that CLT may not be employed in large classes.

There are also challenges derived from CLT's own principles. The major common challenge coming from CLT in EFL contexts is the lack of environment for EFL learners where the learners do not have access to communicative English as they learn the language instrumentally. Instrumental learning is learning English for the purpose of practical reasons such as passing an exam or getting a degree. According to [5] and [17], these learners who learn English instrumentally have low motivation, thus missing one great success factor in the acquisition of a second language. On the other hand, the motivation for those who study English for integrative purposes, such as studying English for the purposes of studying or getting a job in the target community, is higher. 
Other challenges to CLT implementation in EFL contexts coming from CLT itself are time for preparing CLT materials, teachers' heavy teaching load, lack of specific methods for assessing communicative competence [22]; [40]-[42]. The table below further demonstrates all the specific challenges in the implementation of CLT reported from the literature in the EFL contexts mentioned earlier.

Table I: Challenges related to CLT as Reported in the Literature

Challenge 1: Challenges related to Teachers and Students in CLT Implementation

Students
-Learners cannot develop
their communicative skills
-For most learners, learning
English is a duty
-Students have low first

language cognitive resources

-Different levels of students'

English proficiency

-Students' preference to

exam-oriented English

teaching

-Students' proficiency is

weak

-Students' lack of

communication needs

-No interest in class

participation

-Fear of making mistakes

-The new roles of learners

-Non-native English

speaking teachers

Table II: Challenges related to CLT as Reported in the Literature

Challenge 2: Miscellaneous Challenges Related to CLT

\section{-Cultural traditions}

-Heavy teaching load

-Time and Syllabus

constraints

-Limited time available to involve all students

-Fear of making mistakes

-Limited authentic social

environment outside class

-Examination system

-Lack of funding

-A reluctance to be seen as

a "show off" in the

classroom

-Administrative support
Teachers

-Teachers cannot assess students'

communicative competence

-Teachers lack of knowledge in CLT

-Low confidence of using

CLT in teachers

-CLT demands too much

work from the teacher

-The new roles of teachers

-Teacher's preferences to

traditional methods

-Teachers' low English

proficiency

-Low income for teachers

-Not enough language

competence for

communicative teaching method

-Challenges associated with ELT policy

-Time constraints to complete the national curriculum

-Misconceptions about CLT

-Lack of in-service training

-Lack of supervision form

authority

-Large class size

-Classroom situation (sitting

arrangement -seats/chairs)

-Shortage of materials

-Traditional views about

learning and teaching

-Shortage of school facilities
Table III: CLT related - Challenges as Reported in the Literature

\begin{tabular}{|l|}
\hline Challenge 3: Challenges Related to CLT itself \\
\hline -CLT is unable to identify learners and issues in \\
teaching-learning process \\
-It needs more preparation than teacher-centeredness \\
-Lack of training \\
-Parents' attitudes toward English learning and CLT \\
-Mismatch between curriculum and assessment \\
-Fluency versus accuracy \\
-Highly-centralized curriculum \\
\hline
\end{tabular}

\section{CLT IN AFGHANISTAN}

[43] asserts that English was taught through traditional methods such as Grammar-Translation Method and Audio-lingual Method for many years in Afghanistan. This has negatively affected the communicative abilities of Afghan students: many students are passive in English classes in schools and universities. They are expected just to listen to the English instructors' lectures, memorize the lessons by heart and reproduce the same contents on exam papers. There is no activity focusing on the communicative aspects of the language such as listening and speaking. They do not have the opportunity to work in pairs or groups [43]. The students are expected to memorize the grammar and other rules theoretically. In addition, since CLT has been misconceived as not focusing on on accuracy as a great part of the language teaching, CLT has not been viewed as a suitable method in teaching English, particularly by the older generation lecturers, [44]. Based on my observations in the context, currently, the most common teaching methodologies employed in Afghan educational contexts are dominated by the Grammar-translation and Audio-lingual Methods. Yet, to a minimal extent, CLT is also being used in some settings.

CLT, however, has actually been mostly welcomed by Afghan learners and young English lecturers as a method for teaching English. A study by [32] about the perceptions and challenges of Afghan EFL lecturers in implementing CLT has found that CLT is welcomed by many lecturers in Afghanistan although there are many challenges these EFL lecturers faced. Among the challenges are large class size, and students' low interest and low proficiency. This viewpoint, however, is not groundless. Based on my own experience as a lecturer teaching in an Afghan public university, students in an English class may go up to 250 in numbers. While CLT suggests a small class of 30 students for effective implementation of the approach, the huge number of students may definitely affect the implementation of CLT. This is similar with the challenges in Taiwan [22], Iran [39], Bangladesh [18] and China [21] contexts as mentioned earlier. Looking at the complexity of CLT in EFL contexts around the globe and the unique context of Afghanistan, CLT in Afghanistan definitely merits an extensive study.

The other challenge to CLT implementation in Afghanistan is the teachers' low English proficiency. Most of the Afghan 
EFL lecturers have received undergraduate, graduate and/or postgraduate degrees in Afghan universities (except a limited number who studied abroad) where teaching has been all by traditional methods for years [45]; [43]. This has affected the teachers' English language proficiency level which becomes a negative factor in the implementation of CLT in Afghanistan.

Lack of the context for interacting in English for Afghan EFL learners is another issue. Majority of students do not have the chance of being exposed to English language outside the classroom. The teachers are the sole knowledge providers for the students, who passively receive what the teachers provide ([46]-[48]). While the students may be good at writing skills to a certain, the same cannot be said about their speaking skills [44]; [49]-[50]. Some graduates, for example, have failed the interviews given for a job in non-governmental organizations because of their weak English speaking ability, suggesting the lack of communicative competence among Afghan students and graduates.

Moreover, Afghanistan is a developing nation where poverty has stricken many people. The poverty and the four decades of war in the country have resulted in the lack of a stable and powerful government. Consequently, the schools, universities and other institutions lack the essential and immediate equipment [45]; [51]. While CLT needs an equipped classroom with projectors, DVDs and audio and video tapes, majority of Afghan classrooms lack these facilities.

An exam-oriented class is another problem for CLT application in Afghan universities. The students are taught through lectures and then they are assessed through written exams for which they have to rewrite word by word what they have been taught [46]-[48]. This has perhaps demotivated students for participating in CLT related communicative activities.

As all the problems described above may arise from the use of traditional methods of teaching which could not focus on interactional activities, CLT as it underlies on interaction, may have merits in preparing students to be communicatively competent. According to [52], in CLT, which derives from Interaction Hypothesis, students need social interaction to learn the second language. They need communicative activities like pair work, group work and class works to prepare them to process and intake the second language. And so with CLT approach, Afghan EFL learners may improve in their communicative skills with the implementation of CLT and its principles in Afghan EFL classrooms.

Most importantly, Afghanistan needs to provide their learners with the needs of 21 st century. According to [53], in 21st century, students should be taught self-direction, collaboration and working with other people and machines. Thus, with the employment of CLT, Afghan EFL learners would be provided with these skills required of students in 21 st century.

\section{V.RATIONALE FOR FUTURE STUDIES ON CLT IN AFGHANISTAN}

While CLT has been widely used as a teaching method in many ESL and EFL contexts, still very little is known about

CLT and the challenges hindering CLT implementation when it comes to the Afghan EFL setting. The complexity of language teaching and learning in Afghanistan as presented in the previous section merit some scrutiny among scholars and researchers. Nevertheless, there is scarce research about CLT as far as Afghan context is concerned; or at least the majority of the previous studies about CLT have focused on the school domain. There is a shortage of studies regarding CLT in the university level looking at the literature, except for a few.

A study by [32] which examined the Afghan EFL lecturers use of CLT-related activities such as pair work, group work, role plays and so forth found that the lecturers faced significant challenges as large classes, grammar-based examinations, heavy teaching load, lack of support from administration, students' low proficiency and lack of motivation. However, since he used quantitative questionnaire to gather data, which cannot provide a detailed image of CLT employed in Afghan universities, more research is required. [54] mentions that quantitative questionnaire may not provide flexibility for the participants to freely and deeply express their ideas about the topic. To provide flexibility for the participants, open-ended questions and interview should be used to gather more insight. Qualitative interview will help to gain a deep understanding of the Afghan EFL lecturers' perceptions and challenges in implementing Communicative Language Teaching. As [55] argues, interviews may serve as the best tools to find out about the stories behind the participant's experiences. Kvale further states that with interview, we can gain in-depth information around a topic. Hence, qualitative questionnaire should be added in studying the perceptions of Afghan EFL lecturers on the ELT in the Afghan context.

[32] also studied the views of EFL lecturers only in one university in Afghanistan which therefore cannot be used to represent the Afghan EFL lecturers' perceptions based on some unique institutional factors pertinent to Afghanistan.

First, the number of EFL lecturers differs from one university to another. For example, the number of EFL lecturers in English department of Kabul University (38 EFL lecturers) varies from the number of EFL lecturers in English department in Ghazni University (5 EFL lecturers only). The same case is in many other universities of the country and this could give direct implications to teaching loads of the EFL lecturers. As highlighted above, teachers' teaching load may work as a factor in the application of CLT: EFL lecturers with more teaching loads may not be able to apply CLT as CLT demands a lot of preparation such as pair work, group work, using audiovisuals, and applying other CLT related techniques, and vice versa.

In addition, universities also differ from each other based on the available facilities. For example, the universities which have been established ten or twenty years ago possess good facilities with projectors, enough classrooms, and other essential equipment whereas newly established universities such as Ghazni University do not have essential equipment and usually there is not even enough classrooms for students. 
Some universities which are geographically-challenged and have constraints in terms of security may have even lesser facilities for their students. Apart from that, the Afghan public universities also differ from one another based on the qualifications of lecturers. For instance, previously established universities may have lecturers with master's or even the $\mathrm{PhD}$ degrees; newly established universities may just hire lecturers who have only a first degree (e.g. Bachelor of Arts). The difference in lecturers' qualification may possibly affect the application of some teaching techniques, CLT included. Hence, a more comprehensive investigation taking into accounts all the different factors may provide more useful insight into the teaching and learning processes in Afghanistan, particularly on the implementation of CLT.

All in all, there are many different issues in educational domain that may directly or indirectly affect the status of English Language teaching and learning in Afghanistan, which requires further investigation. To sum, the problems such as large classes, teachers' low English proficiency, lack of exposure to second language, poverty and war, exam-oriented classes, extensive use of traditional methods, student' low English proficiency, suggestions from previous researches, lack of holistic research about CLT in Afghan context, meeting the needs and requirements of 21 st century and a contribution to the whole body of research and particularly about Afghanistan make the study appropriate to be conducted.

\section{CONCLUSION}

The paper begins with a description of CLT and challenges and perceptions of CLT among EFL teachers in all contexts around the world before it focuses on the challenges and perceptions of Afghan EFL lecturers regarding CLT implementation in public universities in Afghanistan. The challenges make up the greater part of the paper which are further divided into four categories namely student-related, teacher-related, CLT-related and miscellaneous challenges. While the review on implementation of CLT in the context of Afghan public universities is clearly lacking due to inadequate and limited number of research on CLT in the country, future studies on CLT in Afghan context is thus undoubtedly needed to offer more in-depth insights regarding CLT use in Afghan public universities. As presented, in Afghanistan there are many obstacles that work against the implementation of CLT. Lack of investigations and holistic research about CLT in Afghan context have also been highlighted and this further emphasizes the need to have an in-depth study to examine the perceptions and challenges on the implementation of CLT in Afghanistan for the benefit of improving the teaching and learning of English.

\section{ACKNOWLEDGMENT}

We would like to thank Language Academy of Universiti Teknologi Malaysia for making this paper publication possible.

\section{REFERENCES}

1. Canale, M., \& Swain, M. (1980). Approaches to communicative competence: Seameo regional language centre.

2. Richards, J. C. (2005). Communicative language teaching today: SEAMEO Regional Language Centre Singapore.

3. Criado Sánchez, R. (2009). Taking scripts as a model of lesson organisation for the integration of culture and language in ELT.

4. Littlewood, W. (2007). Communicative and task-based language teaching in East Asian classrooms. Language teaching, 40(3), 243-249.

5. Ozsevik, Z. (2010). The use of communicative language teaching (CLT): Turkish EFL teachers' perceived difficulties in implementing CLT in Turkey.

6. Widdowson, H. G. (1978). Teaching language as communication: Oxford University Press.

7. Savignon, S. J. (1985). Evaluation of communicative competence: The ACTFL provisional proficiency guidelines. Canadian Modern Language Review, 41(6), 1000-1007.

8. Savignon, S. (1990). Communicative language teaching: Definitions and directions. Georgetown University Round Table on Languages and Linguistics, 1, 207-217.

9. Brumfit, C. J., \& Johnson, K. (1979). The communicative approach to language teaching (Vol. 308): Oxford University Press Oxford

10. Jacobs, G. M., \& Farrell, T. S. (2003). Understanding and implementtng the CLT (Communicative Language Teaching) paradigm. RELC journal, 34(1), 5-30.

11. Liao, X. (2000). How CLT became acceptable in secondary schools in China. The Internet TESOL Journal.

12. Savignon, S. J. (2002). Communicative language teaching: Linguistic theory and classroom practice. Interpreting communicative language teaching: Contexts and concerns in teacher education, 1-27.

13. Ying, L. (2010). Communicative activities in ELT classrooms in China. Unpublished master dissertation, University of Wisconsin-Platteville.

14. Ellis, G. (1996). How culturally appropriate is the communicative approach? ELT journal, 50(3), 213-218.

15. Li, D. (1998). "It's always more difficult than you plan and imagine": Teachers' perceived difficulties in introducing the communicative approach in South Korea. TESOL quarterly, 32(4), 677-703.

16. Yu, L. (2001). Communicative language teaching in China: Progress and resistance. TESOL quarterly, 35(1), 194-197.

17. Rao, Z. (2002). Chinese students' perceptions of communicative and non-communicative activities in EFL classroom. System, 30(1), 85-105.

18. Karim, K. M. R. (2004). Teachers' perceptions, attitudes and expectations about Communicative Language Teaching (CLT) in post-secondary education in Bangladesh.

19. Kwon, Y. (2017). A Study of Thai Teachers' Perceptions Toward the Implementation of Communicative Language Teaching of English. HRD JOURNAL, 8(1), 114-125.

20. Abate, E. B. (2014). Prospects and challenges of communicative approach in EFL Context. Prospects, 4(25).

21. Li, P. (2004). Chinese EFL teachers' perceptions of implementation of communicative language teaching at tertiary level. McGill University,

22. Huang, S.-H. (2016). Communicative Language Teaching: Practical Difficulties in the Rural EFL Classrooms in Taiwan. Journal of Education and Practice, 7(24), 186-202. 
23. Kumaravadivelu, B. (2006). TESOL methods: Changing tracks, challenging trends. TESOL quarterly, 40(1), 59-81.

24. Nunan, D. (1987). Communicative language teaching: Making it work. ELT journal, 41(2), 136-145.

25. Islam, M. J., \& Bari, I. S. (2012). Implementation of CLT in Bangladesh and Thailand: Problems and challenges. Outlooks: VUB, 87-105.

26. Sato, K., \& Kleinsasser, R. C. (1999). Communicative language teaching (CLT): Practical understandings. The Modern Language Journal, 83(4), 494-517.

27. Bax, S. (2003). The end of CLT: A context approach to language teaching. ELT journal, 57(3), 278-287.

28. Swan, M. (1985). A critical look at the communicative approach (2). ELT journal, 39(2), 76-87.

29. Hu, G. (2002). Potential cultural resistance to pedagogical imports: The case of communicative language teaching in China. Language Culture and Curriculum, 15(2), 93-105.

30. Kumaravadivelu, B. (2001) TESOL Quarterly, 35 (4), 537-560

31. İnceçay, G., \& İnceçay, V. (2009). Turkish university students' perceptions of communicative and non-communicative activities in EFL classroom. Procedia-social and behavioral sciences, 1(1), 618-622.

32. Noori, A. (2018). Communicative Language Teaching (Clt) In Efl Context: Exploring Afghan Efl Lecturers' Perceived Challenges in Implementing Clt.

33. Abdulkader, F. A. (2016). An Investigation of Saudi EFL Teachers' Perceptions of the Appropriateness of Communicative Language Teaching (CLT) in a Saudi Context. International Journal of Educational Investigations (June: Special Issue),. 3 (6): 42, 68.

34. Vongxay, H. (2013). The implementation of communicative language teaching (CLT) in an English department in a Lao higher educational institution: a case study.

35. Thamarana, S. (2015). A Critical Overview of Communicative Language Teaching. Interna tional Journal of English Language, Literature and Humanities, 3(5), 90-100.

36. Chang, M. (2011). EFL teachers' attitudes toward communicative language teaching in Taiwanese college. Asian EFL Journal, 53(2), 17-34.

37. Vaezi, S., \& Abbaspour, E. (2014). Implementing CLT in the Iranian context:"Reality" versus Theory. Procedia-social and behavioral sciences, 98, 1905-1911.

38. Burnaby, B., \& Sun, Y. (1989). Chinese teachers' views of western language teaching: Context informs paradigms. TESOL quarterly, 23(2), 219-238.

39. Anani Sarab, M. R., Monfared, A., \& Safarzadeh, M. M (2016). Secondary EFL School Teachers' Perceptions of CLT Principles and Practices: An Exploratory Survey. Iranian Journal of Language Teaching Research, 4(3), 109-130.

40. Ntirenganya, J. B. (2015). Rwandan University EFL Teachers' Perceived Difficulties in Implementing Communicative Language Teaching (CLT).

41. Alam, M. (2016). Challenges in implementing CLT at secondary schools in rural Bangladesh.

42. Leal, L. C. (2014). Challenges Perceived by Teachers in the Implementation of Communicative Language Teaching in Chile. Applied Linguistics.

43. Hikmat, A. (2009). The Effects of English Teaching Methods Course of the English Department of Kabul Education University on Secondary School English Teachers.

44. Alamyar, M. N. (2017). Emerging Roles of English in Afghanistan. INTESOL Journal, 14(1).

45. Tobenkin, D. (2014). Revitalizing education in Afghanistan: Overcoming decades of devastation.

International educator, 23(4), 22.

46. Darmal, D. (2009). Assessment Practice and Perception of Social Science Instructors in Afghanistan.

47. Noori, A., Shafie, N. H., Mashwani, H. U., \& Tareen, H. (2017). Afghan EFL lecturers' assessment practices in the classroom.

48. Somaiya. (2017). The Implementation of Communicative Language Teaching Approach in Journalism Faculty of Kabul University. Kabul University: Kabul

49. Zia, Z., \& Sulan, N. (2015). EFL learners' levels of classroom performance anxieties and their causes in classroom speaking activities in Afghanistan International Journal of English and Education, 2(1).

50. Hashim, H., \& Isa, I. S. M. (2012). Students' anxiety level towards speaking in English: Malaysia polytechnic experience. Paper presented at the 2012 IEEE Symposium on Business, Engineering and Industrial Applications.

51. Palau, G. R. (2013). Afghanistan Team Leader \& Social and Strategic Infrastructure Desk Officer: Displacement in Afghanistan: Post-2014 Origins, Current Situation and Potential Flows.

52. Long, M. H. (1990). The least a second language acquisition theory needs to explain. TESOL quarterly, 24(4), 649-666.

53. McCoog, I. J. (2008). 21st Century Teaching and Learning. Online Submission.

54. Creswell, J. W. (2012). Educational research: planning. Conducting, and Evaluating.

55. Kvale, S. (1996). The 1,000-page question. Qualitative inquiry, 2(3), 275-284

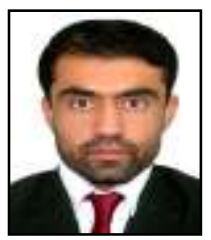

\section{AUTHORS' PROFILES}

Ghazi Mohammad Takal is a full-time lecturer at the Department of English, Faculty of Languages and Literature in Ghazni University, Afghanistan since 2014.He teaches Phonology, Second Language Acquisition, Morphology, Teaching Practice, Translation, Phonetics, Study Skills, ESP classes and Basic Interpersonal Skills. He also has 9 years of experience teaching English at private institutions in Afghanistan and he was a Fulbright participant of AJFDP (Afghan Junior Faculty Development Program in 2017) held in the USA. At the moment, he is pursuing a Master's Degree in TESL at Universiti Teknologi Malaysia and in his final semester

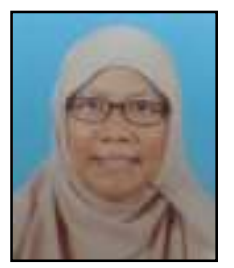

Noor Mala Ibrahim is a senior lecturer at Language Academy, Universiti Teknologi Malaysia, and Johor, Malaysia. Her interests include Corpus Linguistics, Spoken Discourse, Academic Writing, Discourse Analysis and English Language Teaching. She has vast experience in teaching English Language Proficiency and EAP related courses to undergraduate as well as postgraduate students. Currently, she teaches Academic Writing and Effective Writing Skills to TESL undergraduates and supervises several post graduate students in areas of ELT, Discourse Analysis and Academic Writing 